\title{
Research on the Food Supplier Mode of Raw and Fresh E-commerce

\author{
-Based on the Case Study of Cofco's Wo Mai Net
}

\author{
Jinfeng Wang ${ }^{1}$, Jiaguang $\mathrm{Fu}^{1}$, Yongzheng Wang ${ }^{1}$ \\ ${ }^{1}$ School of management and engineering, Zhengzhou University, Zhengzhou, China \\ Jia_guang2013@163.com
}

Keywords: Fresh e-commerce, Food supplier mode, Cofco’s Wo mai Net, Supply chain

\begin{abstract}
The fresh market has a very large market capacity, while the penetration rate of fresh e-commerce is relatively small, so there is a lot of room for development. Although there are many kinds of business models existing in the market, but the truly profitable e-commerce platforms are few. The comprehensive analysis of the advantages and disadvantages of specific business models is of great significance to the improvement of the development of fresh e-commerce. This paper takes the Cofco's Wo mai Net as an example to explore the mode of food suppliers of fresh e-commerce contractor in the food supply chain, storage system, the food hygiene and safety, and the disadvantages of capital, market positioning and logistics system. Based on the advantages and disadvantages of the food supplier model of fresh e-commerce, some feasible suggestions are put forward, so that the food supplier model can develop rapidly.

\section{INTRODUCTION}

vital importance to the development direction of the fresh e-commerce of the model and the optimization of the industrial structure of the fresh electricity business.
\end{abstract}

In 2012, it was regarded as the first year of China's fresh and fresh e-commerce business (Yanhong Cheng,2014). Higher profit margins and strong stickiness prompted fresh agricultural products become the fourth largest category of popular products after books, 3C electronics and clothing, and the new e-commerce system was also maturing in the development (Yumou Yang,2011). At present, there were seven modes: vertical e-commerce, offline supermarket, logistics fresh e-commerce, community $\mathrm{O} 2 \mathrm{O}$, integrated e-commerce platform, farm direct selling and food supplier mode. Although from the current pattern, none of them could truly dominate the fresh market. But combining with the food supply chain, logistics system and food hygiene safety, which were the key conditions that restrict the development of fresh e-commerce, we can find that the food supplier model was undoubtedly the most competitive mode. The perfection and development of this model will definitely promote the growing of the new e-commerce system.

Compared with the large fresh market capacity, the penetration rate of fresh e-commerce was still in the low permeability. With the maturing of the new e-commerce system and the transformation of people's consumption patterns, there was a great potential for the market of fresh e-commerce. At present, the raw and fresh e-commerce was still in the blue sea stage. China's fresh electricity business model will enter the era of resource integration

(Fangqian Luo,2012). The coexistence of various modes and the uneven variety of platforms made the development of fresh e-commerce a lot of problems. China's fresh electricity business cold chain logistics was unreasonable that made the cost become higher

(Yanling Qi,2016), We should strengthen the cold chain logistics and marketing strategies in the future

(Chuanshu Wu,2015). Therefore, the study of the advantages and disadvantages of the special mode of fresh e-commerce and its development prospect are of

\section{RESEARCH OBJECT}

The food supplier mode of fresh e-commerce refered to the traditional food processing enterprises or food marketing enterprises directly into the field of raw and fresh e-commerce, comprehensively utilizing their advantages in the food supply chain, food processing technology, food distribution industry chain, and directly selling fresh fruits, vegetables, meat and other fresh products on the Internet through the use of e-commerce, and can provide a complete model of the necessary services required by the products from producers to consumers.

There are four main elements: trading platform, fresh food supplier, warehousing logistics system and consumer. The role of traditional food suppliers in the fresh e-commerce food supplier model makes it an unattainable advantage in the field of fresh e-commerce. With its own advantages in food processing and circulation, fresh e-commerce can have more bargaining power in the procurement of raw materials under the food supplier mode. The distribution channel and logistics system of traditional food suppliers in the process of storing and products in the process of food storage are an excellent resource for fresh e-commerce.

Therefore, the food supplier model of raw and fresh e-commerce will be a potential force for the development of the whole new e-commerce industry. Cofco's Wo mai Net is a typical representative of the food supplier models. Cofco is the largest food and oil food producer and trader in China, which has been the top 500 company in the world for 20 years

(Zhao Ping,2011). Its main business included grain and oil food processing and sales, agricultural products trade and tourism resort management. The company has a large number of well-known brands, such as the household name "Fu Linmen" cooking oil and "Great 
Wall" wine, which have already occupied a place in the domestic food market (Song Chao,2014).

\section{ADVANTAGES OF FOOD SUPPLIER MODEL}

How to strengthen its own food supply chain, and strengthen the supervision of food hygiene and how to optimize the whole logistics system in the process of circulation of commodities, had become the major raw electrical business survival and development of important factor. Only in these three aspects to accumulate advantages, to form huge competitiveness in electric dealer market.

\subsection{Advantages of food supplier mode in the food supply chain}

Agricultural products supply chain is oriented by market demand and as a link to commercial contracts

(Lipeng Wang, 2010), including agricultural producers, processors, transporters, distributors until the final consumers together as whole (Xianbing Liao,2012), through the whole supply chain of agricultural products logistics, information flow, cash flow control, to meet consumer demand for agricultural products, make consumers have high quality, fast and safe service function nets chain structure(Wang Ke,2014). For the food supply chain of fresh e-commerce, more and more are the effective combination of stable supply relations of commodity suppliers and lower purchasing price.

Cofco has expanded the breadth and depth of the industrial chain of the group through the strategy of building a whole industry chain grain and oil food enterprises. Based on "scale economy" and "cost leadership" of economic theory, not only made Cofco in terms of cost control was superior to other fresh e-commerce company, but also had a greater say in ensuring the priority of raw materials.

Wo mai Net 's food supply chain system was fully undertaken by Cofco,Wo mai Net opened "I buy the characteristic" plate to cover Cofco products comprehensively. In the recommendation of Wo mai Net's plate, mainly provided the Cofco products outside the distinctive quality goods. This not only enriched the level of Wo mai Net's network, but also increased the user's stickiness. It had also strengthened the business relationship between Cofco and other food companies, laid a solid foundation for better supply in the future. On the procurement cost, relying on Cofco's support, Wo mai Net in the process of negotiating with upstream suppliers, can get more bargaining power, which is incomparable advantage over other B2C fresh electricity companies.

\subsection{Advantages of food suppliers in food hygiene and safety}

Food hygiene and safety problems not only harmed the health of the people, but also harmed the image of Chinese food enterprises. People had raised higher and higher requirements for the quality and safety of food! The importance and urgency of food enterprises' effective maintenance of supply chain were also becoming more and more obvious (Xiaoyan Bi,2007). If food safety problems cannot be effectively controlled, it would not only aggravate the panic of ordinary people, but also caused social unrest.

The procurement channel of Cofco was mainly a self-operated base and a large agricultural enterprise. The stable cooperative relationship ensured the quality of raw materials was effectively guaranteed. In accordance with the foreign interpretation of Cofco management "whole grain and oil food industry chain enterprises" the basic connotation of this strategy was the enterprise production of all grain and oil food, consumer can be backed up from the table to be cultivated source in every link of every link to ensured the health and safety, through selecting, planting of the seed (swine) (breeding) management, purchase, storage, processing, packing, transportation and sales control management and so on each link, finally can realize grain and oil food hygiene safety traceability, form a complete from the source to the terminal consumption of grain and oil food industry chain. In this article complete chain, which can ensure provide health and safety of grain and oil food to the end consumer, also can appear to the health and safety of grain and oil food processing in time, avoid the flow to the market.

\subsection{Advantages of food supplier mode in warehousing process}

The construction of a reasonable network of storage facilities could not only ensure the preservation of food, but also arranged the distribution of goods in a reasonable way to optimize the logistics flow. Wo mai Net's grain logistics worked by Cofco's logistics group to undertake, Hualiang logistics group was currently the nation's largest across regional grain logistics enterprises, the logistics system by the northeast corridor, the Beijing-Tianjin corridor, the Yangtze river, southwest of corridor, corridor also included entrepot storage of grain, port, bulk grain cars, ships and other related supporting services. At present, Wo mai Net in Beijing and Shanghai with a normal temperature logistics center and fresh logistics center, which covers a total area of 50,000 square meters. Also in the west of Chengdu logistics center, Wuhan logistics center and logistics center has been put into operation one after another in Guangdong, perfect logistics system for Wo mai Net's logistics operation provides a strong support.

\section{ANALYSIS OF THE DISADVANTAGES OF THE FOOD SUPPLIER}

In the process of food supplier mode operation, there were some problems, such as there was certain pressure in capital, market positioning and logistics terminal. For businesses, these dangers can develop into deadly threats at any moment.

\subsection{Disadvantages of the food supplier model}

Despite the current boom, the market was still in "burning" mode. In the early stage of the brand name recognition and expansion of the market share, the big e-commerce companies launched advertising and planned preferential activities to attract consumers. Such 
as Cofco's Wo mai Net launched the welfare of registered a red envelope, every major holiday sites would distribute a large number of coupons to attract consumers, electricity would not regularly launched low-priced goods to improve sentiment to develop consumer shopping habits.

Although Cofco as traditional food dealers, upstream suppliers in supply had certain advantage for price, can get a little lower than Wal-mart, Carrefour, supply price, but lower profit space compression. The relationship between e-commerce website and traditional food enterprises was complicated, and it was difficult for foreign capital to enter and become one of the reasons for the shortage of fresh e-commerce. If the profit model cannot be innovated, the healthy development of e-commerce would be difficult to sustain.

\subsection{Disadvantages of the food supplier model in market positioning}

Cofco had positioned itself as a national platform for fresh and fresh e-commerce. The target group mainly focused on the high-paying white-collar workers in first-tier cities such as Beijing and Shanghai. This class is characterized by youthful fashion and daring to try fresh. Therefore, it was difficult to improve the stickiness of customers by relying on preferential prices. Nowadays, all major e-commerce platforms had opened fresh plates. As these e-commerce giants continue to join, the industry may face a homogenous problem. At that time, food suppliers will have less and less advantage in the food supply chain, food safety and logistics.

How to penetrate into the market of two, three or even four and five-line cities was particularly important for the national process of fresh e-commerce. However, the market in the second and third-tier cities was more complicated, and people still have a tradition of low recognition of the e-commerce shopping, the lack of awareness of early adopters, and consumption behavior. The market was still a long way to go for fresh e-commerce companies that were currently attacking first-tier cities without a stable market share.

External suppliers were also increasingly worried about fresh suppliers, who fear that if Wo mai Net become a large network, and it will threaten them. How to position the market positioning and balance and the cooperation between the parties is a question worth pondering.

\subsection{Disadvantages of the supplier mode in the cold chain logistics}

For the whole logistics system, the consumers' intuitive feelings about service level were determined by the logistics terminal. How to get through the "last kilometer" of the logistics system was the key to improve the overall service level. At first Wo mai Net choosed third-party logistics companies to provide distribution services for themselves, but its less control over the distribution network work caused it's services being questioned by consumers.

In addition to the response speed of logistics, how to ensure the freshness of fresh food was an important indicator for consumers to evaluate the quality of logistics services (Yunpeng Bai,2013). Fresh food has a certain shelf life, and for the majority of raw and fresh e-commerce, its supporting storage facilities have good preservation ability of fresh food. Therefore, fresh food is less likely to deteriorate in the process of warehousing. Most of the spoilage problems of fresh food appear in the distribution chain, so cold chain logistics is particularly important in the distribution of fresh food.

But because of the cold chain distribution equipment was relatively expensive and operation process was relatively complex, at present, most of the logistics company of cold chain distribution system was still relatively weak, which cannot effectively guarantee the freshness of fresh food in the distribution process. This was a great danger to the healthy development of fresh electricity.

\section{THE TREND OF THE FUTURE DEVELOPMENT OF THE FOOD SUPPLIER MODEL}

With the continuous improvement of science and technology and the improvement of people's living standard, the prospect of fresh e-commerce will be bright, and the competition of future fresh e-commerce will become increasingly fierce. In general, the food supplier model wants to be thriving, it must be optimized from the raw material supply, warehousing distribution and innovative profit model.

\subsection{Operation base and localization operation}

Unlike in the past, when sales were driven by low prices to capture the market, the future of fresh e-commerce must rely on quality to retain consumers. With the improvement of people's living standard, people's pursuit of quality will gradually become the dominant factor of choice. Only in the premise of ensuring food hygienic safety can we continuously expand the variety of quality food to increase the user's stickiness.

Because the dispersed farmers will make the quality of food raw materials more difficult to control, and the unstable supply system will greatly weaken the initiative of fresh e-commerce. It is an important way to reduce the bad cost and improve the operational effect of the agricultural enterprises to reduce the structural level of the agricultural product supply chain and establish the dynamic cooperative relationship (Sun Wei,2004).

Therefore, the future of the food supplier model of fresh electricity business to expand the construction of self-owned base, the implementation of standardization, automation and scale production and to expand their supply system. For some of the smaller demand for food, fresh electricity business should be with the strong qualifications of agricultural products enterprises also strengthen strategic cooperation, in order to ensure the stability of the supply system under the premise of enriching their own types of products. In order to reduce the logistics transport distance, the localized business model is also a development trend. That is, in the local self-built agricultural base and logistics warehousing facilities to provide services to consumers. 


\subsection{Automatic storage and cold chain logistics}

At the fast pace of modern life, the new e-commerce needs to continuously improve logistics efficiency to meet users' needs. Obviously, the current storage facilities are still relatively backward, and the fresh electricity suppliers should speed up the construction of storage facilities to form a more intensive warehousing network system. In terms of warehousing internal facilities, it is important to gradually realize automation to reduce costs while ensuring compliance with preservation standards.

In the aspect of logistics distribution, we should invest more in cold chain logistics to ensure the freshness of food in transportation engineering. To the third party logistics and consumers/third party distribution mode, reduce logistics cost, improve the shopping experience two obvious advantages, localization is a trend of small and medium-sized electricity fresh business enterprise development better choose (Guochen Wei,2015). In addition, with the development of unmanned aerial vehicle delivery technology, it is possible to introduce the delivery of drones to improve distribution efficiency.

\subsection{Innovating profit model}

The current profit model of fresh e-commerce is still relatively unitary. Although gross margins for the food industry is higher, but the offer has been severely compressed electric business profits, close coupled with large investment in advertising made electricity traders lose money USES become the norm.

For future food supplier models to be profitable, there must be an innovative profit model. If the tourism industry is to be developed, it will open its own planting base and food processing enterprises to visit the consumers. In addition to increasing revenue, it can improve the brand awareness in consumers' minds. E-commerce can also expand the market by analyzing consumer shopping habits to develop more quality products.

The future is full of opportunities and challenges for food suppliers, and how to avoid the shortcoming is the key to the market. Only clear positioning and more convenience for consumers can be the final winner.

\section{ACKNOWLEDGEMENTS}

This study is supported by grants from Key Research Programs in Colleges and Universities of Henan Province (Nos.17A630059).

\section{REFERENCES}

[1] Chuanshu Wu, 2015.Study on the Development Model of Freshmen in Foreign Countries [J]. World Agriculture. (5): 136-138.

[2] Fangqian luo, 2015.Mingyu Wang.Study on the Present Situation and Industry Prospect of China's Fresh Electric Merchants [J]. Chinese Journal of Business Administration. (20): 63-65.

[3] Guochen Wei, 2015. Innovation of the logistics mode of e-commerce enterprises[J]. China's circulation economy. (1):43-50

[4] Lipeng Wang., 2010.Research on agricultural supply chain management mode under the perspective of food safety[D]. Tianjin: Tianjin university of technology.

[5] Song Chao, 2014.Strategic study of grain electronic trading business of Cofco group[D]. Dalian: Dalian university of technology.

[6] Sun Wei, Xiaoning Wan, Linyan Sun, 2004.The structure optimization of China's agricultural product supply chain system under e-commerce environment[J]. Industrial engineering and management. (5):33-41.

[7] Wang Ke, Li Zhen, Zhou Jian, 2014.The analysis of the supply chain channel of e-commerce participation take the example of " Food housekeeper "[J]. East China economic management.28(12):157-161.

[8] Xianbing Liao., 2012.Cofco "whole grain and oil food industry chain enterprises" strategic studies[D]. Chengdu: Southwest jiaotong university.

[9] Xiaoyan Bi, Zhang Jin,Liu Tao, Lu Peng., 2007.Research on the selection of food suppliers[J]. Food science and Technology. (5):5-7.

[10] Yanhong Cheng, 2014. Research on the American fresh e-commerce model[J]. The world's agricultural. (8):76-79.

[11] Yumou Yang., 2011.Wo mai Net: creating a food shopping blue ocean [J]. Shanghai's economy. (5):66-68.

[12] Yanling Qi, 2016.Study on the Development of Fresh Electric Enterprises in China [J]. Journal of Statistics and Management. (8): 119-120.

[13] Yunpeng Bai, 2013.The center of Beijing logistics center and the batch selection optimization research on Cofco's Wo mai net[D]. Beijing: Beijing jiaotong university.

[14] Zhao Ping, LuoYi., 2011.Case analysis and Revelations of the development of agricultural e-commerce[J]. Business economics and management. (7):19-23. 